\title{
Speech Recognition Performance of Adults: A Proposal for a Battery for Telugu
}

\author{
S. B. Rathna Kumar \\ Centre for Applied Linguistics and Translation Studies, University of Hyderabad, Hyderabad, India; \\ Ali Yavar Jung National Institute for the Hearing Handicapped, Southern Regional Centre, Hyderabad, India \\ Email: sarathna@yahoo.co.in \\ Panchanan Mohanty \\ Centre for Applied Linguistics and Translation Studies, University of Hyderabad, Hyderabad, India \\ Email: panchanan_mohanty@yahoo.com
}

\begin{abstract}
Speech audiometry is an essential component of the audiological test battery, as it provides information concerning one's sensitivity to speech stimuli and the understanding of speech at supra-threshold levels. With regard to the history of materials for speech audiometry, different kinds of materials have been developed by several investigators in English and non-English languages. Several such attempts have also been made to develop and standardize materials for speech audiometry in Indian languages. With reference to Telugu (South Indian Dravidian Language) no such material is available for measuring open-set speech recognition score in adults. Telugu is mother tongue of the majority of people of Andhra Pradesh (Southern State of India) which is divided into three regions. Although, the mother tongue of majority of people of Andhra Pradesh is Telugu, some of the most familiar and frequently used words in one region may not be familiar to people belonging to other regions due to dialectal variations. The purpose of this study is to develop speech material in Telugu which can be commonly used to assess speech recognition performance of individuals belonging to three regions. Four lists of bisyllabic words in Telugu were developed and equivalence analysis of difficulty between the word lists was evaluated for three groups (from three regions) of subjects (age range of 18-25 years) with normal hearing. Subsequently, performance intensity (PI) function for each list was also measured for the three groups. The results revealed that there was no significant difference $(p<0.05)$ between scores obtained by three groups for each list and between four lists for each group. The four word lists developed were found to be equally difficult for all the groups. The performance-intensity (PI) function curve showed semi linear function, and the linear portion of the curve indicated an average linear slope showing $4.64 \%, 4.62 \%, 4.52 \%$ and $4.54 \%$ increase in word recognition score per $\mathrm{dB}$ for list 1 , list 2 , list 3 and list 4 respectively and were found be in accordance with the findings of earlier studies. The four lists thus developed were found to have sufficient reliability and validity in assessing speech recognition performance.
\end{abstract}

Index Terms - speech audiometry, speech recognition score, equivalence analysis, performance intensity function, reliability, validity

\section{INTRODUCTION}

Speech perception is defined as the process of decoding a message from a stream of sounds coming from the speaker (Borden \& Harris, 1980). The study of speech perception is concerned with the listener's ability to perceive the acoustic waveforms produced by a speaker as a string of meaningful words and ideas (Goldinger, Pisonic \& Logan, 1991). The components of speech perception and production are closely related and have been studied extensively for decades. Hearing is a vital sense that is necessary for the development and maintenance of acoustic communication skills. Hearing is the building block on which our intricate human communication system is constructed. Speech is one of the most important vehicles of human communication system. In order to hear and comprehend speech, it requires good auditory integrity. Individuals with hearing loss are bound to have difficulty in perception of speech. Therefore, it is the essential duty of audiologists to identify, evaluate and rehabilitate aurally handicapped individuals.

Aural rehabilitation refers to services and procedures for facilitating adequate receptive and expressive communication in individuals with hearing impairment (ASHA, 1984). Aural rehabilitation is designed to minimize the communication deficits caused by hearing loss. The first step in this process is a thorough evaluation of the audiological dimensions of the hearing loss. There are several clinical tests, which help the audiologist to make an accurate and effective diagnosis. The evaluation of an individual's hearing involves administering a battery of tests and these assessments collectively complement each other in defining the degree, type and configuration of hearing loss. Audiological evaluations also intend to provide information that describes the functional impact of hearing loss on communication. The principle tool used in the process of evaluating a patients auditory functioning is an audiometer. Audiometer is an electronic device that produces and delivers sounds as a stimulus to the patient and determines the intensity needed for a patient to hear those sounds. The sounds used to test a person's hearing must be clearly specified 
so that his hearing thresholds are both accurate and repeatable. The two most common sound stimuli used clinically to assess hearing are pure tones and speech. Each of them can provide valuable information concerning the integrity of the auditory system. Audiological assessment using non-speech signal such as pure-tones is known as pure-tone audiometry. On the other hand, audiological assessment using speech signal such as syllables, words, sentences etc. is known as speech audiometry.

Pure tone audiometry often thought of as the hearing test that involves presenting a series of pure-tones or beeps to the listener at specific frequencies to establish a person's hearing acuity. The smallest intensity of a sound (pure-tone) that a person needs to detect its presence is called his threshold for that sound. Clinically we define the threshold as the lowest intensity at which the patient responds to the sound at least $50 \%$ of the time. The hearing loss of an individual is usually defined as the average of pure-tone thresholds at $500 \mathrm{~Hz}, 1000 \mathrm{~Hz}$ and $2000 \mathrm{~Hz}$ in the better ear expressed in decibels $(\mathrm{dB})$ with reference to normal thresholds. Pure-tone audiometry reveals the degree and type of hearing loss, and also facilitates the decision as to the need for further tests or medical interventions. The process of pure tone audiometry is uncomplicated and easily administered. "Identification of the stimulus by the listener presumes a relatively simple neural apparatus and the response usually raising the hand is not complex one" (Schill, 1985). Puretone audibility thresholds are an important part of many specialized procedures for testing auditory function as well as in evaluating hearing aids and other rehabilitation devices and in rehabilitation planning.

In spite of having such advantages, pure-tone audiometry alone has many limitations. Pure-tone audiometry does not provide all needed information for assessment of the auditory system. It serves the possibilities but not realities and helps in estimation only. Assessment of hearing using pure tones provide information regarding the sensitivity but not on the receptive auditory ability (Marshal \& Bacon, 1981). The conventional pure tone procedures fail to provide any information about a person's ability to hear above the threshold. Pure tone audiometry can only assess the auditory system's ability to hear a simple stimulus and does not provide information about the individual's ability to understand speech. Ability to perceive pure tones does not require any psychic integration or synthesization thus the results are inadequate in the diagnosis and differential diagnosis of various auditory disorders (Willeford, 1969; in Kholia, 2010, p. 2).

To find out the ability of a patient to hear speech involves testing him with speech stimuli, and this process is called speech audiometry. Carhart (1951) defined speech audiometry as the technique where in standardized samples of a language are represented through a calibrated system to measure some aspect of hearing ability. Speech audiometry means any method of assessing the state or ability of the auditory system of an individual, using speech stimuli or sounds as the response evoking stimuli (Lyregaard, 1976). The above two definitions are broadly similar and they emphasize that the purpose of speech audiometry i.e. to assess the ability of the auditory system to understand speech. According to James Jerger, speech audiometry is best friend in the clinic for audiological diagnosis (Kholia, 2010). Speech stimuli used in speech audiometry vary from consonants, phonetically balanced words, spondee words, digits, non-sense syllables, sentences and even continuous digit discourse. Speech sounds are more meaningful and reflect the critical activities of life and the comprehension of social communication. We live in an oral-aural society and hence the most measurable aspect of human auditory function should be the ability to understand speech. In summary speech tests are generally regarded as clinically more acceptable than pure-tone audiometry for identifying patients with poor auditory analytical capability, because they also involve the assessment of higher-level linguistic activities and the effects of contextual constraints in processing auditory information (Wang, Mannell, Newall, Zhang \& Han, 2007).

\section{BACKGROUND OF THE STUDY}

\section{A. Speech Recognition Score (SRS)}

Speech recognition score (SRS) or word recognition score (WRS) or speech identification score (SIS) is a procedure of establishing the percentage of correctly perceived phonetically balanced monosyllabic words or consonant vowel combination presented at a comfortable supra-threshold level. Evaluating speech recognition score is a method where in the subject is presented with a series of stimuli and is asked to identify what he has heard and results are reported in terms of percentage on the basis of correctly repeated words presented to him. The phonetically balanced lists (PB lists) refer to the list of words consisting of a group of single words so selected that the frequency of occurrence of speech sounds within a group is same as the frequency of occurrence of the same sound in a language. Carhart (1965) recommended the use of monosyllabic words for discrimination test since they are meaningful to the patient and are non-redundant.

\section{B. Clinical Functions of Speech Recognition Score}

Gelfand (2007) has listed the following clinical functions of speech recognition score testing: 1) to describe the extent of hearing impairment in terms of how it affects speech understanding 2) to differentially diagnose auditory disorders by determining the anatomical site of lesion 3) for determining the needs for amplification and other forms of aural rehabilitation devices like cochlear implants, bone anchored hearing aids etc. 4) for making comparisons between various hearing aids, amplification approaches and other forms of aural rehabilitation devices 5) for verifying the 
benefits of hearing aid use and other forms of aural rehabilitation devices 6) for monitoring patient performance over time for either diagnostic or rehabilitative purpose.

\section{Materials Available for Measuring Speech Recognition Score}

With regard to the history of materials for speech audiometry testing, different kinds of materials have been developed by several investigators in English and used in clinics over a long period. The material available in English may not be appropriate for many of the world's other languages due to speaker's specific language or dialect. As it is difficult to test individuals whose native language is not English, there has been a spurt in the attempts to develop speech materials in non-English languages such as Spanish (Christensen, 1995), Italian (Bocca \& Pelligrini, 1950 and Turrini, Cutugno, Maturi, Prosser, Leoni \& Arslan, 1993), Portuguese (Harris, Goffi, Gygi \& Merrill, 2001), Polish (Harris, Nielson, Mcpherson, Skarzynski \& Eggett, 2004), Mandarin Chinese (Nissen, Harris, Jennings, Eggett \& Buck, 2005), Russian (Harris, Nissen, Pola, Mcpherson, Tavartkiladze \& Eggett, 2007) and Tongan (Seaver, 2008). Several such attempts have also been made to develop and standardize speech audiometric materials and tests in Indian languages including PB word list in English on Indian population (Swarnalatha, 1972), PB word list in Hindi (De, 1973), PB word list in Tamil (Dayalan, 1976), PB words in Manipuri (Devi, 1985), PB word list in Kannada ((Yathiraj \& Vijayalakshmi, 2005), PB word list in Mizo (Mangaiahi, 2009), PB word list in Rajasthani (Kholia, 2010). With reference to Telugu (South Indian Dravidian Language) no such material is available for measuring open-set speech recognition score in adults. Hence there is a need to develop such speech material and the current study aimed at developing word lists in Telugu for assessing speech recognition scores in adult subjects.

\section{Telugu (a South Central Dravidian Language Spoken in South India)}

Telugu is South Indian Dravidian language and has the third largest number of native speakers in India, and is $13^{\text {th }}$ in the ethnologic list of most- spoken languages worldwide. It is the official language of Andhra Pradesh (state in south India), one of the largest states of India and the mother tongue of the majority of people of Andhra Pradesh. It is also spoken in such neighboring states as Karnataka, Tamilnadu, Orissa, Maharashtra and Chhattisgarh, and is one of the 22 scheduled languages of India. Niccolo Da Conti in $15^{\text {th }}$ century called Telugu as the 'Italian of the East' as the words in Telugu end with a vowel sound similar to Italian. Telugu is mother tongue of the majority of people of Andhra Pradesh state. Andhra Pradesh is divided into three regions namely Telangana, Rayalaseema and Coastal Andhra. Although, the mother tongue of majority of people of Andhra Pradesh is Telugu, some of the most familiar and frequently used words in one region may not be familiar to people belonging to other regions due to dialectal variations. A number of studies on speech audiometry have indicated that the validity and reliability of speech recognition testing can be influenced by several factors, such as familiarity, words in common usage, normal sampling of speech sounds and so on. The word list developed by keeping in mind 'familiarity and commonly used' words with reference to particular region may not be useful to assess speech recognition performance in people belonging to other regions of Andhra Pradesh. Hence there is a need to develop material for assessing speech recognition score which includes words which are familiar and commonly used by people belonging to all the regions of Andhra Pradesh.

\section{METHOD}

Till date with reference to Telugu language no such material is available for measuring open-set speech recognition performance. The purpose of the study was to develop and evaluate word lists in Telugu for assessing speech recognition performance. In order to fulfill the aim of the study, the following method was adopted. The study was conducted in four phases:

Phase I: Development of word lists in Telugu as a test material for assessing speech recognition performance.

Phase II: Recording of the test material.

Phase III: Equivalence analysis of developed word lists.

Phase IV: Assessing performance-intensity (PI) function of normal subjects.

\section{A. Phase I: Development of Word Lists in Telugu}

The following steps were involved while developing the word lists in Telugu for assessing speech recognition performance: 1) Collection of words 2) Familiarity assessment of collected words 3) Subjective validation of words 4) Pilot study for objective validation of words 5) Construction of final word lists.

1. Collection of words in Telugu

The words were collected from different sources like periodicals, newspapers, magazines, journals, general books, phonetic books and spontaneous speech. This resulted in an accumulation of about 500 words in Telugu. The words collected were disyllabic in structure. These words were further subjected to familiarity assessment, subjective validation and objective validation in order to construct final word lists in Telugu for assessing speech recognition performance.

\section{Assessment of familiarity of the collected words}

The collected words were assessed for familiarity in order to ensure that the selected words were known to native speakers of Telugu and were commonly used by people belonging to different regions of Andhra Pradesh. To assess the familiarity of the selected words, a total of 90 subjects (age range of 18-25 years) from different regions of Andhra 
Pradesh who are native speakers of Telugu language (Coastal Andhra, Rayalaseema \& Telangana) were included. The subjects were further equally subdivided into three groups (30 subjects in each group) based on the above mentioned regions. A three point rating scale was used for familiarity rating as: most-familiar, familiar and unfamiliar. From the obtained results, the words with most-familiar and familiar rating were listed for each group (three regions). The obtained words of most-familiar and familiar rating were further assessed for homogeneity across individuals from the three regions. A hierarchical arrangement of the most-familiar and familiar rated words was done. The words with most-familiar and familiar response from the three different groups were considered for further assessment.

3. Subjective validation of test items

Validity refers to a degree to which a study accurately reflects or assesses the specific concept that the researcher is attempting to measure. Validity is the extent to which the concept one wishes to measure is actually being measured by a particular scale. To fulfill the purpose of validity of words in the test material, content validity was carried out to the words. Content validity is based on the extent to which a measurement reflects the specific intended domain of the content (Caramines, 1991). Content validity is based on logic and expertise. This type of validity is used because this technique helps the researcher to review how the essential test items can attribute the test measures. For the purpose of carrying out the content validity, the developed familiar words were given to six experts working in the field of Speech Language Pathology, Audiology and Linguistics. The experts were explained about the purpose of test procedure and asked to respond whether the words selected would fulfill the purpose. The responses of the experts were collected as agree, disagree and suggestions. Word wise validation of the material was done. A hierarchal arrangement of the agreed words was done. The only words which were agreed by all the experts were selected for further assessment.

4. Pilot study for objective validation of test items

A pilot study is a miniature version of a study that the researcher uses to test the validity of the collected words prior to the actual study. The pilot testing involves administering the test procedure using the collected words on a sample of normal subjects and analyzing the obtained data. This was carried out to ensure whether the words collected on the basis of familiarity assessment and expert validation can fulfill the goal of the speech recognition score testing. It is important that the test procedure be given in a situation that matches the actual circumstances in which test will be done. The pilot study was intended to identify the words which would be recognized or identified by a group of normal hearing subjects at an intensity level where it is expected to be recognized or identified correctly. It is generally expected that high speech recognition scores are obtained at levels of 30-40 dB SL relative to the SRT (Gold, Lubinsky \& Shahar 1981; in Silman \& Silverman, 1991, p.141). Hence a presentation level of 40 dB SL with reference to SRT is used for the pilot study.

\section{a. Subjects}

A total of 45 subjects in the age group of 18-25 years with normal hearing and no speech disorders served as subjects. All the children were native speakers of Telugu language. The subjects were further equally divided into three groups (15 subjects in each group) depending on their region of Andhra Pradesh. Group I: subjects belonging to Costal Andhra region, Group II: subjects belonging to Rayalaseema region and Group III: subjects belonging to Telangana region.

\section{b. Audiometric testing}

The audiometric assessments including otoscopic examination, pure-tone audiometry, speech audiometry and tympanometry were conducted to ensure that suitable subjects with normal hearing were selected for the experimental procedures. The pure-tone average threshold (PTA) and speech recognition threshold (SRT) was obtained for all the subjects using Maico MA 53 diagnostic clinical audiometer with TDH 39 headphones. Tympanometry was carried out using Madson Zodiac 901 middle-ear analyzer.

\section{c. Administration procedure}

The subjects were tested in a sound-treated audiometric room. The examiner presented the speech stimuli using monitored live voice, ensuring that the deflection of the VU meter was zero. A distance of 6-9 inches was maintained between the microphone and the mouth of the tester. Each subject was given following instructions in Telugu "you will listen to the words presented through headphones. Listen carefully and when you hear a word repeat the word in a loud voice". Initially ten practice items were presented in order to familiarize the subjects about the test procedure. If the subjects felt tired during the test, a short break was given. All the words obtained after subjective validation were presented at presentation level of SRT $+40 \mathrm{~dB}$ SL. The stimulus was presented through Maico MA 53 diagnostic clinical audiometer with TDH 39 headphones.

d. Selection of words for constructing final word lists

The words which were correctly recognized or identified by each group of subjects were arranged in a hierarchical order. The words which were correctly recognized or identified by the three groups of subjects were selected for preparing final lists of phonemically balanced bisyllabic words for assessing speech recognition performance. This has resulted in an accumulation of 320 words.

\section{e. Preparation of final bisyllabic word lists}

Classical Telugu consists of 35 consonants, 10 vowels and 2 diphthongs (Ramanarasimham, 1998). When it comes to spoken Telugu the lower mid vowel /æ/ is used in it (Krishnamurti, 1998). Out of the total consonants 23 are considered as core and 12 are considered as non-core phonemes (Ramanarasimham, 1998). Although such a classification of core and non-core phonemes exists in Telugu, the final word lists were prepared based on the frequencies of occurrence of 
the phonemes in the Telugu corpus available in Centre for Applied Linguistics and Translation Studies Language Technology Lab, University of Hyderabad, India. The phonemes which have frequencies of occurrence of equal to or more than 0.5 were only considered while preparing the final word lists. The phonemes on which the test items were constructed were based on the frequencies of occurrence of phonemes in Telugu (Rao \& Thenarasu, 2007). As the number of consonantal phonemes in each word list was coming to 49 and in order to balance the each word list with 50 phonemes (consonant), phoneme /1/ was repeated in the list 1 and phoneme /t/ was repeated in list 2 , list 3 and list 4 as per the convenience. A total four final word lists and one practice word list were prepared for assessing speech recognition performance. All the words were disyllabic with the CVCV structure. However, words like /ūru/ 'village', /eț u/ 'which side' and /ēdi/ 'which one' which are VCV in structure were also included in the final word lists. Due to limited number of words with /ș / in CVCV structure, the word /ș āpu/ 'shop' is included in list 2 and list 4 . Each final word list consisted of 25 words (with a total of 100 words) and a trial list consisted of 10 words. After constructing the four final word lists, each final word list was again randomized into five times forming five different lists (with a total of 20 lists) for further assessment.

\section{B. Phase II: Recording of the Test Material}

The recording was done in a sound treated room and the noise levels were maintained as per the ANSI Guidelines S3.1-1991. Each randomized word list was spoken by a female native speaker of Telugu, and was recorded using 16 $\mathrm{KHz}$ sampling rate and 16 bit quantization using computerized speech lab (CSL) 4500 software. The signal was digitized at a sampling rate of $16 \mathrm{KHZ}$ using a 12 bit analog to digital converter housed within the computer. Each word was saved as a separate file. The recorded material was then edited to carry out noise and hiss reduction. Amplitude normalization of the signals was done using adobe audition (version 3.0) software to maintain the constant amplitude across the words. The inter stimulus interval between the two words was set to 4 seconds. A calibration tone of $1 \mathrm{KHz}$ was inserted before beginning of the word list to adjust the vu meter at zero. The material was then copied onto an audio compact disc using a compact disc writer.

\section{Phase III: Assessing Equivalence Analysis of Word Lists}

A formal study was carried out to evaluate the equivalence between four lists and comparing the performance of three groups for each list for further performance- intensity function assessment. In order to assess the equivalence between lists the following method has been formulated.

\section{Subjects}

A total of 90 subjects in the age group of 18 - 25 years with normal hearing and no speech disorders served as subjects. All the children were native speakers of Telugu language. The subjects were further equally divided into three groups (30 subjects in each group) depending on their region of Andhra Pradesh. Group I: subjects belonging to Costal Andhra region, Group II: subjects belonging to Rayalaseema region and Group II: subjects belonging to Telangana region.

\section{Audiometric testing}

The audiometric assessments including otoscopic examination, pure-tone audiometry, speech audiometry and tympanometry were conducted to ensure that suitable subjects with normal hearing were selected for the experimental procedures. The pure-tone average threshold (PTA) and speech recognition threshold (SRT) was obtained for all the subjects using Maico MA 53 diagnostic clinical audiometer with TDH 39 headphones. Tympanometry was carried out using Madson Zodiac 901 middle-ear analyzer.

3. Administration procedure

A total of 100 words equally divided into four final lists containing 25 words in each list (list 1, list 2, list 3 and list 4 ) were used as stimulus. Each word list was randomized in order for 5 times to form five different lists and a total of 20 different word lists (random 1, random 2, random 3, random 4 and random 5 of list 1, list 2, list 3 and list 4). This was done to avoid order and practice effect. The developed test material was played through a CD player, which was routed through Maico MA 53 diagnostic clinical audiometer and delivered through the TDH 39 headphones. The stimulus was presented at five presentation levels ( $5 \mathrm{~dB}$ SL, $15 \mathrm{~dB}$ SL, $25 \mathrm{~dB}$ SL, $35 \mathrm{~dB}$ SL and $45 \mathrm{~dB}$ SL with reference to SRT). At each presentation level a different randomized list was used. The order of list was also changed. All the subjects were tested monaurally with four lists and ear selection was done randomly. An open set response in the form of an oral response was obtained. If the subject felt tired during the test, a short break was given. The subjects were tested in a sound-treated audiometric room. Each subject was given following instructions in Telugu "you will listen to the disyllabic words presented through headphones. Listen carefully and when you hear a word repeat the word in a loud voice". Initially ten practice items were presented in order to familiarize the subjects about the test procedure. The responses of the subjects were marked as either 0 or 1 . Each correct response was given a score of 1 and an incorrect response was given a score of 0 . The raw score was then converted to percentage as follows:

$$
\text { Total score }(\%)=\frac{\text { Total number of co rrect response }}{- \text { Total number of wo rds presented }}
$$

\section{Phase IV: Performance-Intensity (PI) Function Testing}


Performance-intensity function is a graphical representation of the percentage of words correctly identified or recognized as a function of the intensity level of the words. The group mean and standard deviation values for each list at different presentation levels were calculated. These mean speech recognition scores at different presentation levels were used to obtain performance intensity function curve of each group for four lists. Various researchers have stated that performance of the subjects vary with the level of intensity of presentation of stimulus. Therefore, in order to find out the intensity level at which the performance could be maximum, the presentation level was increased in $10 \mathrm{~dB}$ steps starting from the $5 \mathrm{~dB}$ SL. Curve estimation and regression analysis were carried out in order to find out linearity function of the performance intensity function curve and to find out the average percentage (\%) increase per $\mathrm{dB}$ in word recognition.

\section{ANALYSIS OF RESULTS}

\section{A. Equivalence Analysis of Word Lists}

Speech recognition scores were calculated for each subject of three groups at each presentation level for four lists. Inter-list equivalence analysis was carried out by calculating the mean and standard deviation values of each group score for each list at different presentation levels. The mean and standard deviation values for each list at different presentation level for three groups are summarized in table 1. It has been found that with increase in presentation level, there was a corresponding increase in mean speech recognition scores in all the groups for four lists used. Each list showed normal distribution in all the groups. The data was subjected to ANOVA in order to find out significant difference in speech scores of each group between four lists. The results indicated that there was no statistically significant difference between scores of each group between four lists $(\mathrm{p}<0.05)$. In addition to this the group score comparison was also carried out to find out any significant difference in groups mean score between four lists. The results indicated that there was no statistically significant difference in groups mean score between four lists ( $\mathrm{p}<0.05$ ). Finally the mean score comparison between three groups for each list was also carried out to find out significant difference in scores of each list between three groups. The results indicated that there was no statistically significant difference in mean score of each list between three groups $(p<0.05)$. Hence it can be concluded that all the four lists are equally difficult for all the groups and could be used in testing the PI-PB function.

TABLE 1

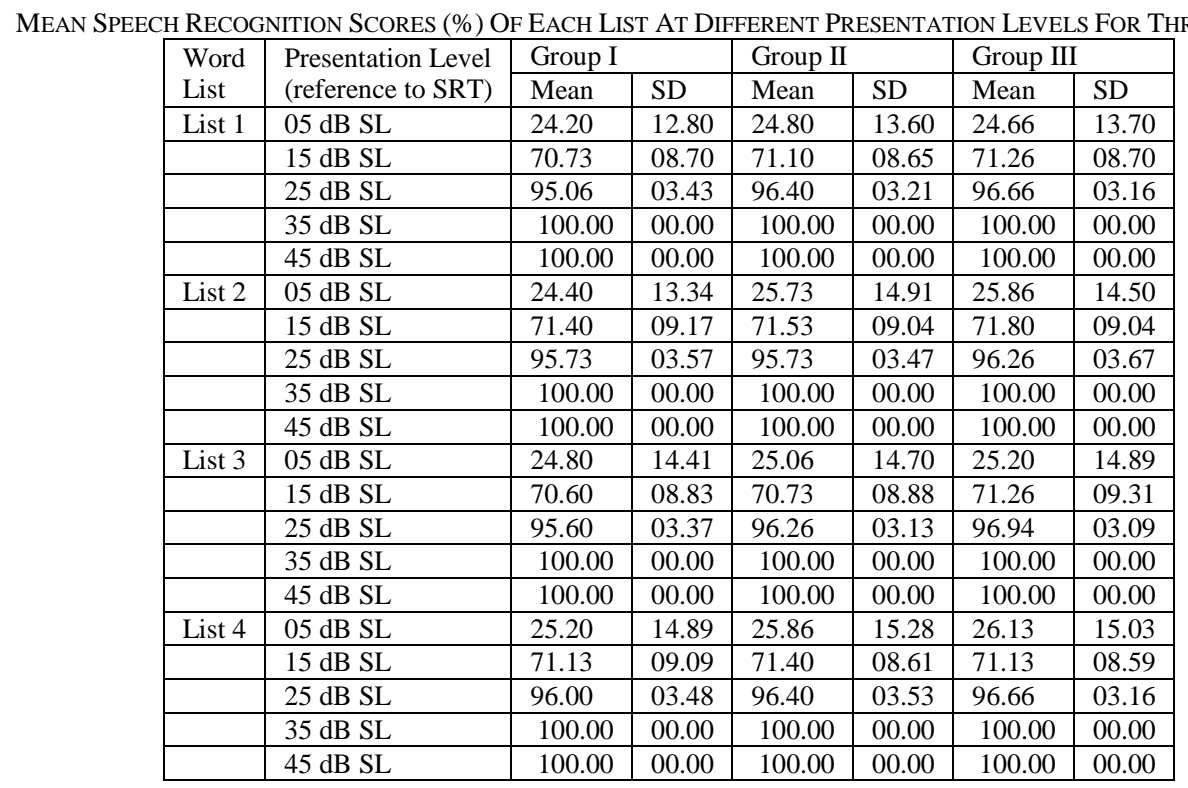

\section{B. Performance-Intensity (PI) Function Testing}

TABLE 2

Group MEAN SPEech ReCOGNITION SCORES (\%) At DifFERENT PRESENTATION LEVELS

\begin{tabular}{|l|c|l|l|l|l|l|l|l|}
\hline \multirow{2}{*}{$\begin{array}{l}\text { Presentation Level } \\
\text { (Reference to SRT) }\end{array}$} & List 1 & \multicolumn{1}{|c|}{ List 2 } & \multicolumn{1}{c|}{ List 3 } & List 4 & \\
\cline { 2 - 9 } & Mean & SD & Mean & SD & Mean & SD & Mean & SD \\
\hline 05 dB SL & 24.55 & 13.36 & 25.33 & 14.25 & 25.20 & 14.66 & 25.73 & 15.06 \\
\hline 15 dB SL & 71.03 & 08.68 & 71.57 & 09.08 & 70.85 & 09.00 & 71.22 & 08.76 \\
\hline 25 dB SL & 96.04 & 03.26 & 96.04 & 03.57 & 95.90 & 03.19 & 96.35 & 03.39 \\
\hline 35 dB SL & 100.00 & 00.00 & 100.00 & 00.00 & 100.00 & 00.00 & 100.00 & 00.00 \\
\hline 45 dB SL & 100.00 & 00.00 & 100.00 & 00.00 & 100.00 & 00.00 & 100.00 & 00.00 \\
\hline
\end{tabular}


Performance-intensity function is a graphical representation of the percentage of words correctly identified or recognized as a function of the intensity level of the words. The group mean and standard deviation values for each list at different presentation levels are summarized in table 2. These mean speech recognition scores at different presentation levels were used to obtain performance intensity function curve of each list for three groups. Figure 1 shows group mean performance intensity function curve for list 1, list 2, list 3 and list 4 . The mean word recognition scores increased as the presentation levels increased and the subjects reached $100 \%$ scores at SRT $+35 \mathrm{~dB}$ SL for all the lists. This remained unchanged thereafter at higher intensity i.e. at SRT $+45 \mathrm{~dB}$ SL. However, the normal range of recognition scores $(90 \%-100 \%)$ was obtained at $25 \mathrm{~dB}$ SL with reference to SRT for all the lists. Clinically the most commonly used sensation levels are 25 to $40 \mathrm{~dB}$ SL. Twenty five dB SL corresponds to beginning of the plateau at which normal hearing subjects attains scores of $90 \%$ or better on most tests, and $40 \mathrm{~dB}$ sensation level represents a reasonably comfortable listening level for normal hearing subjects. The results revealed a narrow standard deviation for extreme presentation levels while broad standard deviation for low and mid presentation levels. When curve estimation and linear regression analysis were carried out, the performance intensity function curve represented a semi-linear function in all the groups. The lower segments of the curves are more linear as compared to less linear higher segments. Linear regression analysis showed that the linear portion of the function indicated an average linear slop showing $4.64 \%$, $4.62 \%, 4.52 \%$ and $4.54 \%$ increase per $\mathrm{dB}$ in word recognition for list 1 , list 2, list 3 and list 4 respectively.

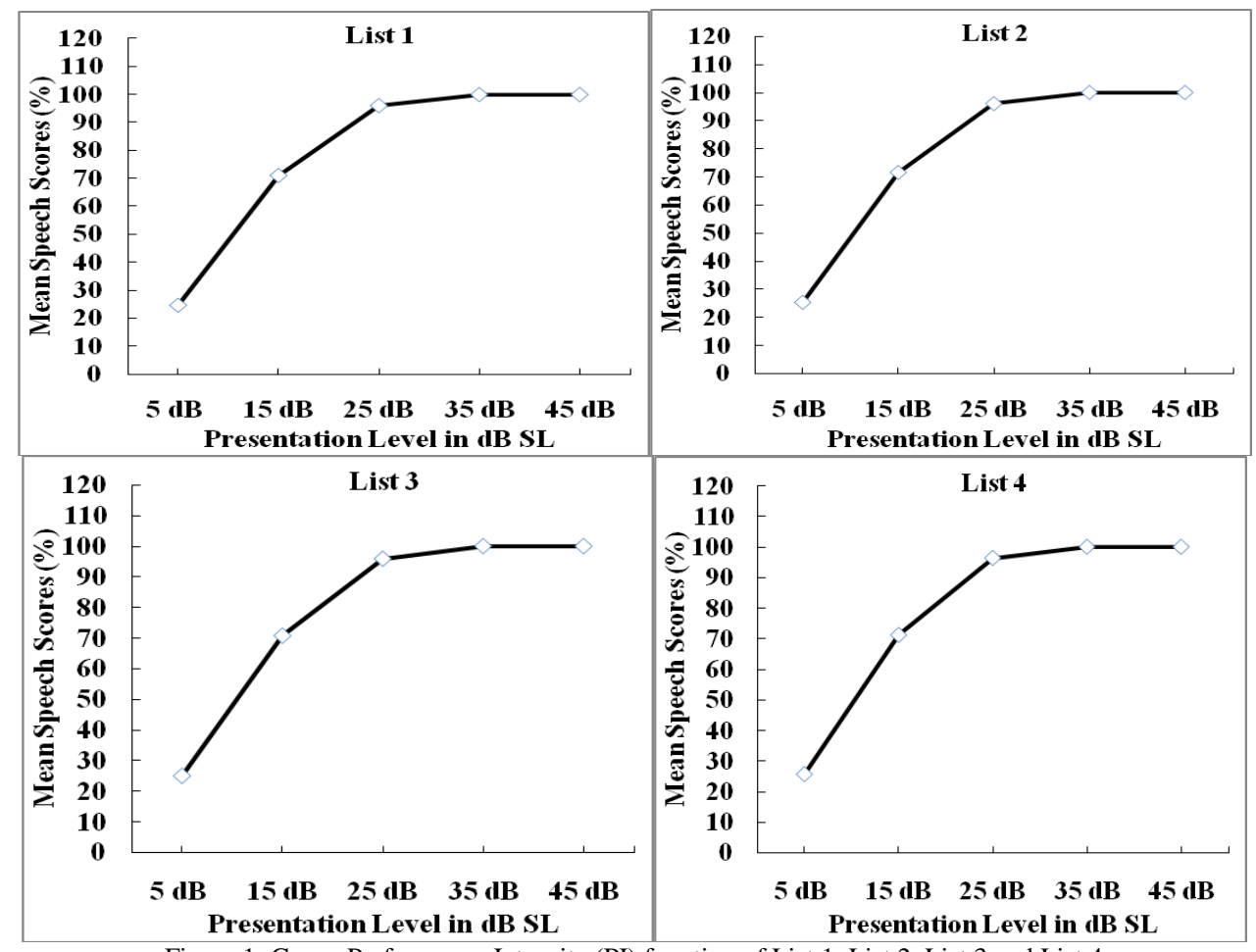

Figure 1: Group Performance Intensity (PI) function of List 1, List 2, List 3 and List 4

\section{DISCUSSION}

Speech audiometry testing is generally regarded as clinically more acceptable than pure-tone audiometry for identifying individuals with poor auditory analytical capability, because they also involve the assessment of higher-level linguistic functions and the effects of contextual constraints in processing auditory information. Telugu is South Central Dravidian language spoken most commonly in Andhra Pradesh a southern state in India. With reference to Telugu, only a limited number of materials have been developed for use in speech audiometry. To date no speech material is available in Telugu to measure open set speech recognition scores in adults. Hence, the current study aimed at developing speech material for assessing speech recognition performance of adults in Telugu. A number of authors have indicated that the reliability and validity of speech audiometry testing can be influenced by factors such as the familiarity, phonetic balance of the words and type of stimulus used (Mackie \& Dermody, 1982; Borden \& Harris, 1980 and Nissen, Harris, Jennings, Eggett \& Buck, 2005).

As mentioned earlier, Telugu is the mother tongue of the majority of people of Andhra Pradesh state which is divided into three regions. Although, the mother tongue of majority of people of Andhra Pradesh is Telugu, some of the most familiar and frequently used words in one region may not be familiar to people belong to other regions. The word list developed by keeping in mind 'familiarity and commonly used' words with reference to particular region may not be effective to assess speech recognition performance in people belonging to other regions of Andhra Pradesh. Hence there is a need of material for assessing speech recognition performance which includes words which are familiar and 
commonly used by people belonging to all the regions of Andhra Pradesh. Hence, by considering 'familiarity' as an important factor in developing the word list, the authors in the current study carried out familiarity assessment among the subjects with different regional background and developed four lists of bisyllabic words.

The concept of phonetic balance played a major role in the development of many speech recognition tests. The phonetically (or rather phonemically) balanced (PB) word lists are a long established tool for the study of speech intelligibility. They generally contain monosyllabic words that have been selected in such a way that the lists reflect the statistical distribution of the phonemes in that dialect. However, phonetic balance has been found to have little practical impact on the outcomes of speech recognition tests, and its clinical relevance is questionable (Carhart, 1970; In Gelfand, 2007, p.274 and Aspinall, 1973; In Gelfand, 2007, p.274). Boothroyd (1968; in Wang et al. 2007, p.1-2) did not follow the concept of phonetic balance and developed the $\mathrm{AB}$ monosyllabic word lists with 10 words in each list, and described the lists as isophonemic, as the thirty most common phonemes appear in each list. Martin, Champlin \& Perez (2000) reported that speech discrimination scores for subjects with hearing impairment or normal hearing did not seem to be affected by whether the word list had phonetic balance or not. Hence, in terms of its relevance to speech recognition testing, the issue of phonetic balance is still an area of dispute (Nissen, Harris, Jennings, Eggett \& Buck, 2005). However, the authors in the current study felt that phonemic balance is important at least for consonants.

Vowels are produced without obstruction in the airflow and perceived better than consonants because they are voiced and relatively high in intensity. Vocal tract is relatively open for them producing prominent resonance for vowels. The first two formant frequencies (F1 \& F2) are essential for the discrimination of the vowel sounds. Vowels are more accessible to auditory analysis by virtue of their longer duration and may hold longer duration in the auditory memory (Stevens, 2002). On the other hand, consonants are produced with the obstruction in the airflow. Consonants are classified according to whether they are voiced or unvoiced, by manner of production (stops, fricatives, nasals etc.) and by place of production (labial, alveolar, palatal etc.). Consonant sound identification is more dependent upon the ability to receive the higher frequency components. If these are inaudible, the place of consonant articulation cannot be determined, thus precluding identification. Although, most of the consonants contain the least power than vowels, these consonants are the ones which provide the major contributions of speech intelligibility. They are affected by loss of intensity rapidly than vowels. Hence, consonants are less accessible to auditory analysis due to their brevity and relatively low intensity, and held briefly in auditory memory (Stevens, 2002). Thus it could be inferred from the above information that perception of consonants is much more complex than vowel perception, due to the low intensity, more susceptible to degradation and varied classifications. This makes it a priority to consonantal aspect of phonemic balance in the word lists. Hence, the authors in the study considered that consonantal aspect of phonemic balance is reasonable while developing the word lists.

Another important aspect is the type of speech material used for assessing speech recognition scores. Monosyllabic words are generally used for assessing speech recognition scores, because monosyllabic words are minimum meaningful unit of a language and are non-redundant. Monosyllables are adequately available in languages like English and other Indian languages, because they are both vowel and consonant ending languages. But some are vowel ending languages where the occurrence of monosyllabic words will be minimal. In such languages it is difficult to construct phonetically balanced monosyllabic word lists because of the inadequate occurrence of meaningful monosyllables. In language like Italian, bisyllabic words are most frequently used as compared to monosyllabic words for developing speech material in evaluating intelligibility function (Turrini, Cutugno, Maturi, Prosser, Leoni \& Arslan, 1993). Bocca \& Pelligrini (1950) and Turrini, Cutugno, Maturi, Prosser, Leoni \& Arslan (1993) developed disyllabic words as a material for speech audiometry. This could be attributed to the reason that, there are very few monosyllabic words in Italian, and most of them are function words (Pagliuca \& Monaghan, 2010) since Italian is a vowel ending language. Similarly in Kannada (south Indian Dravidian language) disyllabic words are used to assess speech recognition scores (Yathiraj \& Vijayalakshmi, 2005) as Kannada is also a vowel ending language.

The authors in the current study also faced difficulty in collecting monosyllabic words for constructing test material in Telugu. There are very few monosyllabic words in Telugu as compared to bisyllabic words (Rao \& Thenarasu 2007). Moreover, most of the monosyllabic words in Telugu do not convey meaning when they occur in isolation. These monosyllabic words gain meaning only when they occur in combination with some other word. This could be attributed to the reason that Telugu is yet another vowel ending language like Italian and Kannada. Hence, Niccolo Da Conti in $15^{\text {th }}$ century called Telugu as the 'Italian of the East' as the words in Telugu and Italian end with a vowel sound. Disyllabic words are frequently occurring minimum meaningful units of Telugu language. Hence disyllabic words were used in constructing test material for assessing speech recognition performance in Telugu. In summary speech recognition scores are the percentage of correctly identified or recognized monosyllabic words, provided the language contains adequate number of meaningful monosyllabic words. However, languages which end with vowel do not contain adequate number of meaningful monosyllabic words and hence disyllabic words can be used since they are the most frequently occurring minimum meaningful units of that particular language. Hence it can be concluded that speech recognition score is the percentage (\%) of correctly identified or recognized test words which are minimum meaningful units of a language and less redundant and presented at comfortable supra-threshold level.

A total four final word lists and one practice word list were prepared for assessing speech recognition performance. All the words were disyllabic with the CVCV structure. However, words like /ūru/ 'village', /eṭ u/ 'which side' and 
/èdi/ 'which one' which are VCV in structure were also included in the final word lists. In Dravidian languages, especially in Telugu, the words beginning with front vowels $/ \mathrm{i} /, / \overline{\mathrm{i}} /, / \mathrm{e} /$ and $/ \overline{\mathrm{e}} /$ are preceded by the palatal glide $/ \mathrm{y} /$ when they occur in the initial position. Similarly, the words beginning with back vowels $/ \mathrm{u} /, / \overline{\mathrm{u}} /, / \mathrm{o} /$ and $/ \overline{\mathrm{o}} /$ are preceded by labial glide /w/ when they occur in initial position. Hence, the words like /ūru/, /eț u/ and /ēdi/ are considered as [wūru], [yet u] and [yēdi] respectively in this study. In order to keep the phonemic balance and due to limited number of words with /ș / in CVCV structure, the word /ș äpu/ 'shop' is included in list 2 and list 4. It is felt that this would not present problems, as there were a total of 100 disyllabic words in the lists (see appendix).

There are four different methods commonly used to determine the reliability of tests of speech recognition, including test-retest reliability, inter-list equivalence, split-half method and inter-item consistency reliability (Mackie \& Dermody, 1982). In this study, the equivalence of difficulty between four lists of Telugu bisyllabic words was evaluated. The four lists developed in the study showed normal distribution and there was no statistically significant difference found between four lists for each group at each presentation level. When the data was further analyzed to identify significant difference in mean scores of each group, it was found that there was no significant difference found between three groups for each list. Hence, the four lists were found to have equal difficulty and these word lists can be used interchangeably for any group of subjects in clinical practice.

There are three categories of methods commonly used to determine the validity of tests of speech recognition, including construct validity, criterion related validity and content validity. Criterion-related validity indicates the validity of a test predicting an individual's behavior in specified situation (Anastasi, 1968). In this study performanceintensity function curve, which is the percentage correct identification of speech stimulus as a function of stimulus intensity, was measured. The standard deviation values reduced as the presentation level was increased in the mean performance-intensity function test. The results revealed a narrow standard deviation for extreme presentation levels while broad standard deviation for low and mid presentation levels. This indicates that at higher presentation levels the subjects' performance became less variable. This may occur because, as the presentation level increases, the relevant phonetic cues would become more reliably audible to these normally-hearing subjects. As the presentation level decreased the responses from the subjects became more variable. This may occur because phonetic cues would become less reliably audible and responses would increasingly depend upon guessing the words.

The group mean slope of the linear portion of the PI-PB function for Telugu bisyllabic words shows $4.64 \%, 4.62 \%$, $4.52 \%$ and $4.54 \%$ increase per $\mathrm{dB}$ in word recognition for list 1, list 2, list 3 and list 4 respectively. Beattie, Edgerton \& Svilhovec (1977) reported a mean slope of $4.2 \%$ per $\mathrm{dB}$ and $4.6 \%$ per dB for English materials, the NU-6 word lists and the CID W-22 word lists respectively and for Indian materials, the authors Dayalan (1976), Devi (1985) and Kholia (2010) reported a mean slop of $3.0 \%$ per $\mathrm{dB}, 5.4 \%$ per $\mathrm{dB}$ and $3.7 \%$ per $\mathrm{dB}$ for Tamil, Manipuri and Rajasthani PB word lists respectively. The normal range of speech recognition score (90\%-100\%) was obtained between $25 \mathrm{~dB}$ SL and $45 \mathrm{~dB}$ SL stimulus presentation levels for all the lists. It is generally expected that high speech recognition scores are obtained at levels of 30-40 dB SL relative to the SRT (Gold, Lubinsky \& Shahar 1981; in Silman \& Silverman, 1991, p.141). Although, there is no other speech recognition test for adults available in Telugu language, most of the findings of the study are in line with the findings of earlier researchers.

\section{CONCLUSION}

Speech audiometry is an essential component of the audiological test battery, as it provides information concerning one's sensitivity to speech stimuli and the understanding of speech at supra-threshold levels. Speech perception skills must be assessed routinely using valid and reliable clinical assessment methods suitable for native speakers of language. The current study developed four bisyllabic word lists in Telugu for assessing speech recognition performance in adults. They were found to be equally difficult, reliable and valid test material in Telugu. To continue the studies on the developed speech material, the test material can be administered on hearing impaired population and other clinical population to check the applicability. This test material can be used in selecting appropriate rehabilitative options and also to measure the efficacy of different rehabilitative devices. The same test material can be used to further develop speech in noise (SPIN) test, time compressed speech test, filtered speech test and other special test for differential diagnosis of auditory disorders.

\section{ACKNOWLEDGEMENT}

The author would like to sincerely thank the following who provided constant help in conducting this study. Our students: Phaninder, Yamini, Madhu, Nagaraju, Divya, Priyanka, Soubhagya, Anil and Srinivas and our colleagues: Prof. Umamaheswara Rao, Centre for Applied Linguistics and Translation Studies, University of Hyderabad for providing the frequency lists of Telugu and Prof. Ramanarasimham, Department of Telugu, University of Hyderabad for providing information on Telugu. 
Appendix I: Frequency Of OCcurrence Of Phonemes In Telugu

\begin{tabular}{|c|c|c|c|c|c|c|c|c|}
\hline S. No. & Telugu Letter & Phonetic Symbol & $\begin{array}{l}\text { Occurrence Per } \\
100 \text { Phonemes }\end{array}$ & $\begin{array}{c}\text { Occurrence Per } \\
50 \text { Phonemes }\end{array}$ & N L1 & N L2 & N L3 & N L4 \\
\hline 1. & $\xi ్$ & $\mathbf{k}$ & 7.80 & 3.90 & 4 & 4 & 4 & 4 \\
\hline 2. & ఖ్ & kh & 0.30 & 0.15 & 0 & 0 & 0 & 0 \\
\hline 3. & గ్ & $\mathrm{g}$ & 3.80 & 1.90 & 2 & 2 & 2 & 2 \\
\hline 4. & ఘ్ & gh & 0.10 & 0.05 & 0 & 0 & 0 & 0 \\
\hline 5. & బ్ & $\dot{\mathbf{n}}$ & 0.00 & 0.00 & 0 & 0 & 0 & 0 \\
\hline 6. & చ్ & c & 3.90 & 1.95 & 2 & 2 & 2 & 2 \\
\hline 7. & ఛ్ & ch & 0.60 & 0.30 & 0 & 0 & 0 & 0 \\
\hline 8. & జ్ & $\mathbf{j}$ & 1.20 & 0.60 & 1 & 1 & 1 & 1 \\
\hline 9. & ఝ & jh & 0.00 & 0.00 & 0 & 0 & 0 & 0 \\
\hline 10. & $\Re^{E}$ & $\tilde{\mathbf{n}}$ & 0.10 & 0.05 & 0 & 0 & 0 & 0 \\
\hline 11. & ట్ & t & 3.80 & 1.90 & 2 & $2+1$ & $2+1$ & $2+1$ \\
\hline 12. & ఠ్ & thh & 0.10 & 0.05 & 0 & 0 & 0 & 0 \\
\hline 13. & $\bar{\epsilon}$ & $\stackrel{+}{d}$ & 3.80 & 1.90 & 2 & 2 & 2 & 2 \\
\hline 14. & $\bar{\zeta}$ & ḍh & 0.00 & 0.00 & 0 & 0 & 0 & 0 \\
\hline 15. & ణ్ & $\underline{n}$ & 0.90 & 0.45 & 0 & 0 & 0 & 0 \\
\hline 16. & త్ & $t$ & 5.90 & 2.95 & 3 & 3 & 3 & 3 \\
\hline 17. & $థ ్$ & th & 0.40 & 0.20 & 0 & 0 & 0 & 0 \\
\hline 18. & ద్ & d & 4.60 & 2.30 & 2 & 2 & 2 & 2 \\
\hline 19. & ధ్ & dh & 0.90 & 0.45 & 0 & 0 & 0 & 0 \\
\hline 20. & స్ & $\mathbf{n}$ & 12.10 & 6.05 & 6 & 6 & 6 & 6 \\
\hline 21. & ప్ & $\mathbf{p}$ & 5.70 & 2.85 & 3 & 3 & 3 & 3 \\
\hline 22. & ఫ్ & ph & 0.30 & 0.15 & 0 & 0 & 0 & 0 \\
\hline 23. & బ్ & $\mathbf{b}$ & 1.50 & 0.75 & 1 & 1 & 1 & 1 \\
\hline 24. & భ్ & bh & 0.80 & 0.40 & 0 & 0 & 0 & 0 \\
\hline 25. & మ్ & $\mathbf{m}$ & 5.70 & 2.85 & 3 & 3 & 3 & 3 \\
\hline 26. & య్ & $\mathbf{y}$ & 4.10 & 2.05 & 2 & 2 & 2 & 2 \\
\hline 27. & $\delta \bar{~}$ & $\mathbf{r}$ & 9.00 & 4.50 & 5 & 5 & 5 & 5 \\
\hline 28. & ల్ & 1 & 8.80 & 4.40 & $4+1$ & 4 & 4 & 4 \\
\hline 29. & ప్ & $\mathbf{w}$ & 5.90 & 2.95 & 3 & 3 & 3 & 3 \\
\hline 30. & ళ్ & 1 & 0.70 & 0.35 & 0 & 0 & 0 & 0 \\
\hline 31. & $\overline{7}$ & $\dot{s}$ & 1.20 & 0.60 & 1 & 1 & 1 & 1 \\
\hline 32. & ష్ & $\mathbf{S}$ & 1.00 & 0.50 & 1 & 1 & 1 & 1 \\
\hline 33. & స్ & $\mathbf{S}$ & 4.30 & 2.15 & 2 & 2 & 2 & 2 \\
\hline 34. & హ్ & $\mathbf{h}$ & 0.80 & 0.40 & 0 & 0 & 0 & 0 \\
\hline 35. & อ. & $\mathbf{R}$ & 0.30 & 0.15 & 0 & 0 & 0 & 0 \\
\hline
\end{tabular}

NL 1, NL 2, NL 3 and NL 4 - Number of phonems in List 1, List 2, List 3 and List 4 respectively.

$* / \mathbf{d} /$ has an allophone [r] which usually occurs in an intervocalic position. But there is no separate letter in Telugu for [r] and it is always represented by the phonetic symbol [ḍ] i.e. '६్' in Telugu. 


\begin{tabular}{|c|c|c|c|c|c|c|c|c|}
\hline \multicolumn{9}{|c|}{ APPENDIX II: FINAL WORD LISTS } \\
\hline $\mathbf{N}$ & \multicolumn{2}{|c|}{ List 1} & \multicolumn{2}{|c|}{ List 2} & \multicolumn{2}{|c|}{ List 3} & \multicolumn{2}{|c|}{ List 4} \\
\hline 1 & పాత & pāta & కోతి & kōti & పాట & pāṭa & తోట & tōtạa \\
\hline 2 & నేను & nēnu & గోడ & gōḍa & కూర & kūra & నూనె & nūne \\
\hline 3 & యాస & yāsa & రేటు & rētu & జాలి & jāli & రైతు & raitu \\
\hline 4 & జేబు & jēbu & బాతు & bātu & ఏది & ${ }^{\#} \bar{e} \mathbf{d i}$ & వేడి & wēdi \\
\hline 5 & పేరు & pēru & గాలి & gāli & నోరు & nōru & నీకు & nīku \\
\hline 6 & లేదు & lēdu & దారి & dāri & కోడి & kōḍi & షాపు & șāpu \\
\hline 7 & కాలు & kālu & తేలు & tēlu & లైటు & laitu & గోరు & gōru \\
\hline 8 & తేనె & tēne & నాకు & nāku & ఫోకు & șōku & లేడు & lēḍu \\
\hline 9 & రాడి & rauḍi & సేవ & sēwa & వాడు & wāọu & కాశి & kāśīi \\
\hline 10 & వాన & wāna & రోలు & rōlu & మూల & mūla & రాను & rānu \\
\hline 11 & షాకు & ṣāku & నీడ & nīḍa & చీర & cīra & సైగ & saiga \\
\hline 12 & మీరు & mīru & కసి & kasi & గౌను & gaunu & పాలు & pālu \\
\hline 13 & సూది & sūdi & నూరు & nūru & దోశ & dōśa & లారి & lāri \\
\hline 14 & చాలు & cālu & జోకు & jōku & రైలు & railu & నాది & nādi \\
\hline 15 & మేక & mēka & శని & śani & మేత & mēta & చాట & cāṭa \\
\hline 16 & టీవి & țīwi & చేయి & cēyi & నస & nasa & నెల & nela \\
\hline 17 & వాగు & wāgu & దోమ & dōma & ఊరు & ${ }^{\#} \mathbf{u} \mathbf{r u}$ & సరే & sarē \\
\hline 18 & కోటు & kōṭu & పాపు & șāpu & బోను & bōnu & మాట & māṭa \\
\hline 19 & లోయ & lōya & నేల & nēla & ఎటు & \# eṭu & వాత & wāta \\
\hline 20 & చారు & cāru & రాయి & rāyi & పూస & pūsa & బావ & bāwa \\
\hline 21 & పైన & paina & పాము & pāmu & నీతి & nīti & మాయ & māya \\
\hline 22 & మూడు & mūụu & విను & winu & మూగ & mūga & జామ & jāma \\
\hline 23 & లేను & lēnu & టోపి & tōpi & తోక & tōka & పీక & pīka \\
\hline 24 & రాశి & raśi & చీమ & cīma & వీపు & wīpu & చేదు & cēdu \\
\hline 25 & తీగ & tīga & వోటు & wōṭu & చేను & cēnu & కాయ & kāya \\
\hline
\end{tabular}

\# In Telugu, the words beginning with front vowels $/ \mathrm{i} /, / \mathbf{i} /, / \mathbf{e} / \& / \overline{\mathbf{e}} /$ are preceded by the palatal glide $/ \mathbf{y} /$ and back vowels $/ \mathbf{u} /, / \overline{\mathbf{u}} /, / \mathbf{0} /$ and $/ \overline{\mathbf{o}} /$ are preceded by labial glide $/ \mathbf{w} /$ when they occur in initial position. Hence, the words in the lists /ūru/, /ețu/ and /ēdi/ are considered as [wūru], [yețu] and [yēèi] respectively in this study.

\section{REFERENCES}

[1] Anastasi, A. (1968). Psychological Testing, $3^{\text {rd }}$ Ed. Macmillan, New York.

[2] ASHA, (1984). Definition of and Competencies for Aural Rehabilitation. ASHA Desk Reference, 4:37-41.

[3] Aspinall, K. B. (1973). In S. A. Gelfand (Ed). Essentials of Audiology, $2^{\text {nd }}$ Ed (p. 274), Thieme Medical Publishers, New York.

[4] Beattie, R. C., Edgerton, B. J. \& Svilhovec, D. V. (1977). A Comparison of the Auditec of St. Louis Cassette Recordings of Nu-6 and CID W-22 on a normal-hearing population. Journal of Speech and Hearing Disorder, 42: 60-64.

[5] Bocca, E. \& Pelligrini, A. (1950). In Santerelli, R., Filippi, R. D., Genovese, E., \& Arslan, E. (2008): Cochlear Implantation Outcome in Prelingually Deafened Young Adults. Audiology \& Neurotology, 13: 257-265.

[6] Boothroyd, A. (1968). In Wang, S., Mannell, R., Newall, P., Zhang, H. \& Han, D. (2007): Development and Evaluation of Mandarin Disyllabic Materials for Speech Audiometry in China. International Journal of Audiology, 46(12): 719-731.

[7] Borden, G. J. \& Harris, K. S. (1980). Speech Science Primer: Physiology, Acoustics and Perception of Speech, Williams and Wilkins. Baltimore.

[8] Caramines, E. G. (1991). Reliability and Validity Assessment, Sage Pub, Newburg Park.

[9] Carhart, R. (1951). Basic Principles of Speech Audiometry. Archives of Otolaryngology, 82: 253-260.

[10] Carhart, R. (1965). Problem I Measurement of Speech Discrimination. Archive of Otolaryngology Head and Neck Surgery, 82: 253-266.

[11] Carhart, R. (1970). In S. A. Gelfand, Ed. Essentials of Audiology, $2^{\text {nd }}$ Ed (p. 274), Thieme Medical Publishers, New York. 
[12] Christensen, L. K. (1995). Performance Intensity Functions for Digitally Recorded Spanish Speech Audiometry. Master's Thesis: Brigham Young University.

[13] Dayalan, S. (1976). Development and Standardization of Phonetically Balanced Test Materials in Tamil Language. Unpublished Master's Dissertation: University of Mysore.

[14] De, N. S. (1973). Hindi PB List for Speech Audiometry and Discrimination Test. Indian Journal of Otolaryngology, 25 : 64-75.

[15] Devi, E. T. (1985). Development and Standardization of Speech Test Material in Manipuri Language. Unpublished Master's Dissertation, Mysore: University of Mysore.

[16] Gelfand, S. A. (2007). Essentials of Audiology, $2^{\text {nd }}$ Ed, Thieme Medical Publishers, New York.

[17] Gold, S., Lubinsky, R. \& Shahar, A. (1981). In S. Silman \& C.A. Silverman (1991) (Eds), Auditory Diagnosis, (p.141), Academic Press, Inc. New York.

[18] Goldinger, S. D., Pisonic, D. B. \& Logan, J. S. (1991). On the Nature of Talker Variability Effect on Recall of Spoken Word Lists. Journal of Experimental Psychology: Learning, Memory and Cognition, 17: 152-162.

[19] Harris, R. W., Goffi, M. V. S., Gygi, M. A. \& Merrill, A. (2001). Psychometrically Equivalent Brazilian Portuguese TriSyllabic Words Spoken by Male and Female Talkers. Pro-Fono, 13, 37-53.

[20] Harris, R. W., Nielson, W. S., Mcpherson, D. L., Skarzynski, H. \& Eggett, D. L. (2004). Psychometrically Equivalent Polish Bisyllabic Words Spoken by Male and Female Talkers. Audiofonologia, 25: 1-15.

[21] Harris, R. W., Nissen, S. L., Pola, M. G., Mcpherson, D. L., Tavartkiladze, G. A. \& Eggett, D. L. (2007). Psychometrically Equivalent Russian Speech Audiometry Materials by Male and Female Talkers. International Journal of Audiology, 11(1): 4766.

[22] Kholia, L. (2010). Development and Standardization of Speech Material in Rajasthani Language. Unpublished Master's Dissertation, Mysore: University of Mysore.

[23] Krsihnamurti, Bh. (1998). Telugu: In S. B. Steever, Ed. The Dravidian Languages (pp. 202-240), Routledge, New York.

[24] Lyregaard, P. (1976). On the Relation between Recognition and Familiarity of Words. National Physical Laboratory Acoustic Report Ac 78.Teddington, Uk: Npl.

[25] Mackie, K. C. \& Dermody, P. J. (1982). Word Intelligibility Tests in Audiology for the Assessment of Communication Adequacy, Australian Government Publishing Service. Canberra.

[26] Mangaiahi, L. (2009). Development and Standardization of Spondee and Phonetically Balanced (PB) Word List in Mizo Language. Unpublished Master's Dissertation: University of Mysore.

[27] Marshall, L. \& Bacon, S. P. (1981). Prediction of Speech Discrimination Scores from Audiometric Data. Ear and Hearing, 2: 148-155.

[28] Martin, F. N., Champlin, C. A. \& Perez, D. D. (2000). The Question of Phonetic Balance in Word Recognition Testing. Journal of American Academy of Audiology, 11: 489-493.

[29] Nissen, S. L., Harris, R. W., Jennings, L., Eggett, D. L. \& Buck, H. (2005). Psychometrically Equivalent Mandarin Bisyllabic Speech Discrimination Materials Spoken by Male and Female Talkers. International Journal of Audiology, 44: 379-390.

[30] Pagliuca, G. \& Monaghan, P. (2010). Discovering Large Grain-Sizes in a Transparent Orthography: Insights from a Connectionist Model of Reading for Italian. Journal of Cognitive Psychology, 22(5): 813-825.

[31] Ramanarasimham, P. (1998). Old Telugu: In S. B. Steever, Ed. The Dravidian Languages (pp. 181-201), New York: Routledge.

[32] Rao, G. U. \& Thenarasu, S. (2007). PGDCAIL: CAIL-421. Corpus Linguistics, University of Hyderabad.

[33] Schill, H. A. (1985). Thresholds for Speech: In J. Katz (Ed), Handbook of Clinical Audiology, $3^{\text {rd }}$ Ed (pp. 224-234). Williams \& Wilkins, Baltimore.

[34] Seaver, L. C. (2008). The Development of Word Recognition Materials for Native Speakers of Tongan. Master's Thesis: Brigham Young University.

[35] Stevens, K. N. (2002). Toward A Model For Lexical Access Based On Acoustic Landmarks. Journal of Acoustic Society of America, 111(4):1872-1891

[36] Swarnalatha, K, C. (1972). Development and Standardization of Speech Material in English for Indians. Unpublished Master's Dissertation, Mysore: University of Mysore.

[37] Turrini, M., Cutugno, F., Maturi, P., Prosser, S., Leoni, F. A. \& Arslan, E. (1993). Bisyllabic Words for Speech Audiometry: A New Italian Material. Acta Otorhinolaryngologica Italica, 13, 63-77.

[38] Wang, S., Mannell, R., Newall, P., Zhang, H. \& Han, D. (2007). Development and Evaluation of Mandarin Disyllabic Materials for Speech Audiometry in China. International Journal of Audiology, 46(12): 719-731.

[39] Willeford, J. (1969). In Kholia, L. (2010): Development and Standardization of Speech Material in Rajasthani Language. Unpublished Master's Dissertation, Mysore: University of Mysore.

[40] Yathiraj, A. \& Vijayalakshmi, C. S. (2005). Phonemically Balanced Word List in Kannada. Developed in Department of audiology, AIISH, Mysore.

S. B. Rathna Kumar is working as Lecturer in Speech and Hearing at Ali Yavar Jung National Institute for the Hearing Handicapped, Southern Regional Centre, Secunderabad, India and pursuing Doctoral Studies in the area of Auditory Phonetics at Centre for Applied Linguistics \& Translation Studies, University of Hyderabad, India.

Panchanan Mohanty is working as Professor of Applied Linguistics at Centre for Applied Linguistics \& Translation Studies, University of Hyderabad, India and Head of Centre for Endangered Languages and Mother Tongue Studies, University of Hyderabad, India. 